\title{
Potencializando a experiência de internacionalização: reflexões sobre o Programa Ciência sem Fronteiras
}

\section{Empowering the internationalization experience: reflections about Science without Borders Program}

\author{
Maria Janine Dalpiaz Reschke \\ Maria Cláudia Fogaça Bido**
}

\section{Resumo}

A qualidade do ensino superior vem incluindo a dimensão da internacionalização como um diferencial e se impondo na agenda das universidades brasileiras. Neste estudo, buscou-se compreender as contribuições do Programa Ciência sem Fronteiras, dando ênfase à perspectiva dos estudantes beneficiados com bolsas no exterior. Esse tema faz parte de uma pesquisa mais ampla sobre a relação/tensão entre internacionalização e democratização da educação superior no Brasil. Os dados foram coletados por meio de entrevistas com os estudantes on-line e presenciais em duas universidades. Os achados foram organizados em dimensões e analisados de acordo com o referencial teórico baseado em Knight e de Wit. Os resultados indicaram a relevância do programa como capital cultural individual dos estudantes, porém, ficou latente a pouca potencialização dessas experiências pelas instituições de origem, em uma perspectiva coletiva, que apontassem para processos de democratização dos saberes e viveres dos beneficiados. No entanto, há indícios de avanços na qualidade do ensino de graduação, no que tange às formas de ensinar e aprender, visando à autonomia e ao protagonismo dos estudantes e a um maior alinhamento entre as instituições de origem dos estudantes e as instituições internacionais.

Palavras-chave: Ciência sem Fronteiras. Internacionalização. Mobilização acadêmica. Universidade.

\section{Abstract}

The quality of higher education has been including the internationalization dimension as a diferential in Brazilian universities agenda. In this study, the objective is to understand Science without Borders contributions, with emphasis to the students who were benefited with scholarships abroad. This topic is part of a broader research on the relation/tension between internationalization/democratization of higher education in Brazil. Data has been collected through online interviews and in person with students from two universities. These findings have been organized in different dimensions and analyzed according to theoretical referential based on Knight and de Wit. The results indicated the relevance of the Program as individual cultural capital acquired by the students, though it became obvious little possibility of sharing their experiences by their home institutions, under a collective perspective, which pointed to the process of democratization of knowledge and experiences of the

Recebido em: 03/07/2016 - Aprovado em: 26/11/2016

http://dx.doi.org/10.5335/rep.v24i1.

Professora da Universidade Luterana do Brasil, Unidade Gravataí, RS. Doutora em Educação pelo Programa de Pós-Graduação em Educação da Universidade do Vale do Rio do Sinos. E-mail: mjanine@terra.com.br

** Professora de inglês no Yázigi Estância Velha. Mestra em Educação pela Universidade do Vale do Rio do Sinos. E-mail: mfogacabido@yahoo.com.br 
benefited ones. However, there are indications of advancements in the quality of undergraduate level, related to ways of teaching and learning, with the objetive of providing student's autonomy and protagonism, and also a stronger alignment between the institutions of origin and the international ones.

Keywords: Science without Borders. Internationalization. Academic Mobility. University.

As reflexões propostas neste texto são derivadas do projeto e relatório da pesquisa interinstitucional intitulada Democratização e internacionalização como desafio: a complexa relação para a qualidade da educação superior no Brasil, desenvolvida em instituições de ensino superior, ${ }^{1}$ tendo como foco a pedagogia universitária e a relação entre a democratização, a internacionalização e a qualidade do ensino de graduação.

A pesquisa pauta-se por importantes questionamentos, desenvolvidos no projeto inicial: serão incompatíveis as duas perspectivas democratização e internacionalização? A origem e a trajetória dos estudantes interferem na compreensão que possuem de qualidade acadêmica? Essa compreensão se altera no percurso acadêmico? As políticas acadêmicas acompanham essas expectativas? Preponderam algumas delas? Esses questionamentos estimularam o desenvolvimento e foram enriquecidos ao longo do processo de investigação, que teve como objetivos:

a) compreender como os programas de mobilidade estudantil de caráter internacional se instituem como referentes da qualidade da formação acadêmica;

b) analisar as compreensões de qualidade da educação superior dos estudantes e como as trajetórias individuais e coletivas interferem nessa construção conceitual;

c) relacionar as compreensões de qualidade da educação superior e perceber como se aproximam e impactam as práticas e as experiências pedagógicas nas universidades, em um contexto de democratização e internacionalização.

As perguntas e os objetivos mobilizaram o estudo e instigaram a examinar como, na prática, diferentes atores percebem a relação entre democratização e internacionalização e se há alguma preponderância entre esses dois fatores incidindo na qualidade do ensino de graduação.

O projeto foi organizado em seis subgrupos de trabalho, que atenderam diferentes eixos investigativos, dentre eles o que conduziu este texto. Nesse contexto, procuramos compreender a experiência dos estudantes de graduação em mobilidade acadêmica e verificar os impactos dessas experiências na formação, nas trajetórias de vida bem como no cotidiano das instituições de origem desses sujeitos.

A amostra envolveu estudantes que participaram do Programa Ciência sem Fronteiras $(\mathrm{CsF})$, considerado um marco na história da mobilidade acadêmica bra- 
sileira. O programa foi criado pelo Decreto $\mathrm{n}^{\circ} 7.642$, de 13 de dezembro de 2011, com o objetivo de oferecer 101 mil bolsas de estudos, distribuídas em centenas de universidades, em 22 países, priorizando dezoito áreas ligadas à ciência e tecnologia. Segundo Bido (2015, p. 58-61), o principal diferencial, em relação ao que as agências de fomento já haviam promovido quanto à mobilidade acadêmica, foi o foco na graduação e, com menor intensidade, na pós-graduação. Com a oferta de bolsas de estudos no exterior, o decreto apresenta diversos objetivos, resumidamente: promover a formação dos estudantes, dando-lhes a oportunidade de novas experiências educacionais e profissionais, visando ao desenvolvimento de projetos de pesquisa, estudos, treinamentos e capacitação em instituições de excelência no exterior. Dessa forma, o CsF procurou gerar oportunidades de cooperação entre grupos de pesquisa, seja de forma institucional ou one-to-one (entre dois pesquisadores), com o objetivo de contribuir para o processo de internacionalização das instituições brasileiras, dando maior visibilidade às realizações acadêmicas e competitividade às empresas brasileiras.

\section{Refletindo sobre o conceito de internacionalização}

O fenômeno da internacionalização está ligado ao surgimento da universidade como instituição na Europa, na Idade Média. Além de a definição territorial apresentar uma configuração muito diferente da atual, naquele continente, a diversidade de recrutamento de estudantes foi o primeiro indício da complexidade dos laços que uniam as universidades à sociedade do seu tempo e impulsionadora da criação de novas instituições, em decorrência de conflitos. Em As universidades da Idade Média, Verger explica que a estruturação da universidade como instituição surgiu por meio de "[...] corporações de professores (Paris), de estudantes (Bolonha) e de repúblicas de estudantes estrangeiros, organizadas por país de origem, chamadas "nações"' (1990, p. 61). O autor relata que a presença de docentes e discentes de diversos países nas instituições gerou conflitos, que redundaram na criação de novas universidades, como Orleans e Cambridge.

Até mesmo a tão renomada Harvard University (EUA) aproveitou-se da experiência na Europa. Charles Eliot, seu reitor, no intervalo entre duas gestões - de 1863 a 1865 -, teve permanência na França, Alemanha e Inglaterra. No retorno à cidade de Cambridge (EUA), Eliot adicionou saberes em alto grau de especialização à sua prática na gestão de Harvard, os quais viriam a ser aplicados em solo americano e representariam, até hoje, o modelo mundial que causou "mutações permanentes na estrutura genética universitária dos EUA" (CHRISTENSEN; EYRING, 2014, p. 47-49). 
Ao avaliarmos a internacionalização no Brasil, vemos que os movimentos ocorrem tanto entre conceituadas e tradicionais instituições de ensino superior, como entre as mais modernas e inovadoras. Stallivieri (2015) afirma que estamos vivendo a terceira geração da internacionalização. Vejamos, então, as três gerações, segundo a autora:

- A primeira fase caracterizou-se por ações esporádicas e assistemáticas, pois eram iniciativas isoladas de professores e pesquisadores com pouca clareza sobre os propósitos institucionais. "Havia pouco protagonismo institucional; a mobilidade estudantil apresentava-se frágil e as parcerias acadêmicas eram menos representativas [...]" (2015, p. 10-11).

- Um segundo momento foi após a declaração da Unesco, durante a Conferência Mundial sobre o Ensino Superior, em 1998, que colocou como imperativo o forte estabelecimento de ações de cooperação internacional, visando à mobilidade de seu corpo docente, à empregabilidade de seus graduandos e vislumbrando uma forte inserção internacional. Essa fase caracterizou-se por importantes avanços, quando foi possível perceber o caráter de reciprocidade, tais como: definição de políticas e criação de estruturas e setores próprios, entre outros.

- O terceiro e atual momento apresenta enorme crescimento de ações voltadas para a internacionalização, em uma "exacerbada multiplicação de acordos e de parcerias internacionais", que necessitam de gestão proporcionalmente ágil. Esse terceiro momento corresponde às demandas dos desafios globais da atualidade e de um novo perfil educacional, em que há:

[...] a responsabilidade de formação de um novo cidadão, preparado para os desafios globais, com importantes competências para a atuação em mercados multiculturais e que, busca, na experiência internacional e no domínio de línguas estrangeiras, um diferencial e um forte elemento competitivo para inserção no exigente mercado de trabalho (STALLIVIERI, 2015, p. 11).

Mesmo percebendo essa classificação como uma síntese, ela ajuda a compreender a internacionalização do ensino superior no contexto contemporâneo, que pode ocorrer de diferentes formas, envolvendo o ensino, a pesquisa ou a extensão, incluindo: 
a) a mobilidade de estudantes, professores, pesquisadores de um país para o outro;

b) os estágios em empresas e universidades;

c) as oportunidades de desenvolvimento de estudo compartilhado com pesquisadores no exterior;

d) os programas de dupla diplomação;

e) a vinda de estrangeiros para as instituições a fim de realizar palestras, ministrar aulas por algum tempo, manter contato com pesquisadores locais;

f) o estudo de língua estrangeira no exterior e da língua local por parte dos estrangeiros e a vivência em ambientes culturais diferentes.

A mobilidade acadêmica é frequentemente associada à internacionalização como sinônimas. A possibilidade, entretanto, de promover estudos no exterior a estudantes de um determinado país (outbound), assim como de atrair para certa instituição alunos estrangeiros (inbound), não constitui por si só a internacionalização. Os autores considerados referência no estudo do fenômeno da internacionalização, sobretudo americanos, canadenses e europeus, discutem há mais de trinta anos a sua definição. Entre tantos conceitos apresentados, analisados e refeitos, destaca-se: "Internacionalização em nível nacional, setorial e institucional é o processo que integra a dimensão internacional, intercultural ou global ao propósito, às funções, objetivos e oferta da educação pós-secundária” (KNIGHT, 2005, p. 11).

Percebe-se que a definição de Knight (2005) incorpora a ideia de processo, usada para abrigar a noção de que internacionalização é um esforço contínuo, em progressão, e não uma ação isolada. Já de Wit e Hunter expandem o conceito anterior:

Internacionalização é o processo intencional de integração de uma dimensão internacional, intercultural ou global no propósito, nas funções e na oferta de educação pós-secundária, a fim de aprimorar a qualidade da educação e da pesquisa para todos os estudantes e corpo docente e fornecer uma contribuição significativa para a sociedade (2015, p. 285).

Por meio de uma releitura do conceito, os autores citados buscam explicitar aspectos valorizados na atualidade, tais como: internacionalização de currículo, foco em melhores resultados de aprendizagem, partindo de mudanças curriculares que preconizem a perspectiva das competências interculturais e globais, melhor uso da diversidade em sala de aula e forte aquisição linguística. a) Embora a mobilidade acadêmica não seja sinônimo de internacionalização, a possibilidade de ir e vir de estudantes, docentes e de pessoas dos quadros administrativos das instituições superiores "permanecerá sendo o pilar que fundamenta o fenômeno da internacionalização”, segundo de Wit e Hunter (2015, p. 43). 
Há consenso entre esses e outros autores, porém, que o fenômeno é polissêmico pela sua própria natureza, pois varia de um país para o outro, conforme a história de cada nação, as perspectivas e os propósitos dos envolvidos. "Provavelmente, nunca haverá uma definição universal”, afirma Knight (2005, p. 10-13).

Nesse contexto, compreendendo a polissemia de conceitos e possibilidades, é importante conhecer como o programa $\mathrm{CsF}$ vem sendo gerido nas universidades e como os estudantes beneficiados manifestam suas aprendizagens e perspectivas. Assumimos a importância formativa de tal programa, mas cremos ser necessário aprofundar o seu potencial para impactar a qualidade da educação superior. Que repercussões tem havido na universidade? O que aprendem os estudantes? Como percebem as experiências de ensinar e aprender que vivem no exterior? Qual o valor dado à internacionalização como elemento de qualificação da educação superior? Que sugestões dariam para aperfeiçoar o programa em nível estatal e institucional? Como vem sendo potencializado o capital cultural acumulado nessa experiência? Como pensam que o Brasil pode se beneficiar com esse investimento?

\section{0 caminho metodológico}

Para desenvolver a investigação, selecionamos duas universidades comunitárias que aderiram ao $\mathrm{CsF}$, localizadas na região metropolitana de Porto Alegre. O critério mais relevante foi o número de estudantes vinculados ao programa. Definimos como interlocutores os estudantes que usufruíram do CSF, independente dos cursos em que estavam.

Inicialmente, por meio da análise de conteúdos, foi realizada a leitura dos documentos reguladores do programa, tanto em nível federal como institucional. $\mathrm{Na}$ continuidade, foram realizadas entrevistas on-line com os estudantes e também com grupos focais. Previamente, foi enviado um convite por e-mail e os interessados compareceram nas universidades no local e na data combinados.

Com o intuito de organizar os dados coletados, foi produzido um quadro-síntese, utilizado como referente para análise. Seguindo o roteiro da entrevista, os dados foram organizados em sete dimensões: (1) motivações; (2) condições de estudo; (3) currículo; (4) metodologia; (5) relação professor e aluno; (6) aprendizagens e desafios; (7) internacionalização. A ênfase deste estudo refere-se às dimensões: (4) metodologia, (6) aprendizagens e desafios e (7) internacionalização.

Visto que o estudo tinha o objetivo de analisar a internacionalização como condição que qualifica o ensino universitário, convidamos os estudantes a relatar os processos curriculares e metodológicos que encontraram nas instituições de ensino superior em que permaneceram. Foi unânime a percepção de terem encontrado uma metodologia centrada na aprendizagem e no protagonismo dos alunos. 
Nesse sentido, a carga horária curricular envolve tanto as aulas presenciais como o tempo que o aluno, de forma monitorada pelas atividades propostas, dedica à sua aprendizagem. Dependendo do país, pode haver variações nessas experiências. É interessante observar o argumento de um estudante de engenharia nesse sentido: "Foi preciso estudar muito. No Brasil o engenheiro deve se formar para construir prédios, pontes... na Itália tudo já está construído e o graduando deverá se empenhar na manutenção ou em algo totalmente novo. Para isso, os conhecimentos de base são fundamentais".

Alguns estudantes viveram experiências curriculares que valorizaram, por exemplo, mais aulas por dia, mas com intervalos entre elas, para os estudantes se organizarem para as inúmeras tarefas propostas pelos professores: "Muitas leituras e um bom número de exercícios eram comuns para nós... Em geral não se espera que o aluno participe ativamente na aula; sua atuação se dará depois, no trabalho independente" (Alemanha). Ainda que haja algumas críticas a esse deslocamento do ensino para a aprendizagem, essa parece ser uma tendência forte nos países para onde nossos alunos se dirigirem.

Certamente, isso tem a ver com a disponibilidade nas bases informatizadas e na imprevisibilidade de maior estabilidade do conhecimento. Os estudantes precisam, já na graduação, desenvolver habilidades de estudo e autonomia intelectual. $\mathrm{E}$ os brasileiros que fizeram esse deslocamento estranharam, pois, no Brasil, ainda temos o ensino presencial como a principal perspectiva de percurso curricular. "Muitas vezes madruguei nas salas de estudo e laboratórios de computação da universidade" (EUA). "Lá os professores dão cases a cada início da aula, sobre a matéria anterior, para serem resolvidos e também é avaliada a participação do aluno" (EEUU). Certamente, nesses casos, há uma concepção de conhecimento e de aprendizagem que repercute nas metodologias de ensinar e aprender, inclusive nos saberes que os professores reconhecem para a docência.

Alguns estudantes afirmaram que, apesar de as universidades (Inglaterra e EEUU) terem muitos e equipados laboratórios, não é comum entender que a pesquisa é parte da formação de graduação. Alguns dos participantes tiveram de insistir e mostrar que, no Brasil, essa inserção pode ser feita muito mais cedo, e é desejável que isso aconteça. Assim, quando aberta essa oportunidade, eles tiveram de conviver com colegas da pós-graduação.

Apenas um dos nossos interlocutores viveu uma experiência de aprendizagem baseada na metodologia de problemas (Problem Project Based Learning - PBL) no campo da engenharia (Países Baixos), prevendo a execução de projetos com um semestre de duração. "Foi muito valioso para mim", afirmou o estudante. Estágios fizeram parte da formação dos alunos brasileiros no exterior, como uma experiência 
bastante valorizada, em que tiveram maiores condições de relacionar a teoria à prática e vislumbrar temas para os seus trabalhos de conclusão de curso (TCCs), envolvendo possíveis transferências e adaptações de tecnologias à realidade brasileira.

É certo que o que foi vivido pelos alunos é diverso. Dependendo do país, da universidade, do curso, das experiências prévias e de tantos outros fatores. Dessa forma, são complexas as generalizações. Muitas vezes, os depoimentos são contraditórios e dependentes das condições objetivas das experiências vividas.

Para o intuito desta pesquisa, um dos objetivos foi compreender as principais aprendizagens que os estudantes vivenciaram na experiência propiciada pelo CsF. Foi surpreendente o destaque que nossos interlocutores deram às aprendizagens pessoais: "Tive de enfrentar tudo sozinha, estar longe da minha cultura e ter de adaptar às aulas em uma língua diferente foi difícil" (EEUU). Os estudantes mencionam impasses desde a moradia, pelas exigências das imobiliárias, quando os campi não tinham essa estrutura, até a gestão da bolsa, “[...] organizando gastos e aprendendo a viver sozinho" (Canadá). O respeito às diferenças culturais foi outro aspecto ressaltado pelos estudantes: "Quando se lida com pessoas tão diferentes em sua base cultural, algumas coisas que tínhamos aprendido como certas ou erradas temos de reaprender, pois esta é uma noção que se altera nas diferentes culturas" (Portugal).

Os alunos também revelam que amadureceram na experiência: “[...] tomar decisões e saber me virar sozinha foi o que mais valorizei, me tornei mais responsável e mais madura para a vida adulta" (Coreia do Sul). Talvez essas sejam aprendizagens complexas para computar nos históricos escolares dos estudantes, entretanto, são fundamentais na sua formação e no futuro desempenho como profissional e cidadão. Cada país, com suas peculiaridades, marcou um tipo de experiência, desde os horários que regem a vida dos espanhóis, até a culinária coreana e inglesa. Mas, para além das diferenças, uma estudante ressaltou que percebeu: "As pessoas são iguais em qualquer parte do mundo, independentemente de usar burca ou ter olhos puxados" (Coreia do Sul). Nesse caso, a igualdade refere-se à condição humana, que envolve sentimentos e identidades. Foram muitas, também, as aprendizagens cognitivas e dos campos específicos de formação mencionadas pelos nossos interlocutores. Muitas menções foram feitas sobre a aprendizagem e a fluência da língua estrangeira, em especial o inglês, mas avanços na área da computação e aprofundamentos teóricos em seus campos profissionais também foram bastante mencionados, inclusive fazendo relações com os percursos acadêmicos vivenciados no Brasil.

No que tange ao valor da internacionalização, os participantes da pesquisa acreditam que o aprendizado propiciado pelo intercâmbio tem significativo valor para a vida pessoal e profissional, bem como na democratização da educação supe- 
rior. Vivenciar diferentes culturas e métodos de ensino possibilitou uma formação diferenciada, preparando-os para os desafios da vida e do mercado de trabalho.

Por intermédio dos relatos, percebemos que os respondentes, em geral, têm a expectativa de poder compartilhar suas experiências no retorno ao Brasil. Muitos relatam que podem e querem contribuir de alguma forma com a universidade e com o desenvolvimento de projetos que possam qualificar suas áreas de conhecimento e sua relação com a sociedade. "Alunos de intercâmbio têm em suas mãos uma vivência acadêmica muito valiosa, eu espero que as universidades no Brasil saibam explorar tudo que estamos aprendendo e levando conosco" (Estados Unidos).

Alguns estudantes destacaram que a aprendizagem adquirida é transformadora e que se sentem em condições de participar de movimentos que possam também transformar a realidade da sociedade natal:

"É uma grande oportunidade para todos que realmente querem aprimorar sua vida estudantil e profissional. A qualidade de ensino pode ser melhor em outros países, porém as experiências adquiridas lá fora, podem mudar o nosso ensino atual e fazer dele algo melhor" (Coréia do Sul).

"Tive a oportunidade de cursar na universidade mais antiga da Ásia, além de a mesma possuir forte relação com a Samsung. Através disso, tive a chance de, então, fazer meu estágio na Samsung, realizando um grande sonho" (Coréia do Sul).

Os acadêmicos entrevistados salientaram, ainda, que seria interessante receber mais alunos de outros países no Brasil, estabelecer outras relações e parcerias, pois quem vem de fora também tem muito a contribuir com a interculturalidade e o desenvolvimento local. Contudo, também apontaram que existe muita burocracia para ampliar os intercâmbios com outros países, bem como alertaram para a necessidade de melhorar a infraestrutura de recepção aos alunos estrangeiros. Os estudantes demonstram interesse em aproveitar suas experiências para contribuir com suas instituições de origem, ao retornar do intercâmbio. Em geral, registraram a ausência de iniciativas nesse sentido. As experiências são compartilhadas de forma muito restrita nas aulas, com os colegas mais próximos.

A "prestação de contas" acaba restringindo-se a um relatório de viagem, que é entregue à agência de fomento. "É necessário apenas um melhor controle sobre o aproveitamento dos estudos dos bolsistas, pois este controle tem sido um pouco distante" (Alemanha). O aprendizado e o conhecimento que adquiriram tem um importante significado pessoal, pois cada um ressignifica a experiência para si, mas creem que seria importante uma dimensão mais coletiva.

Os relatos apontam para o valor da internacionalização na educação superior, apesar das restrições apontadas para o pleno desenvolvimento do CsF. Além disso, há o reconhecimento de sua importância e das aprendizagens que propicia, ampliando as perspectivas de vida e de formação de seus participantes. 


\section{Reflexões finais}

A vivência internacional propiciada por uma política pública tal como o Programa Ciência sem Fronteiras, para um volume considerado grande de bolsas, que permitiu estudos acadêmicos de seis a dezoito meses no exterior, é algo para ficar na história da educação brasileira e que precisa ser potencializado. A experiência colocou o Brasil em contato direto com algumas das instituições que são referência em suas áreas no cenário mundial e possibilitou a exposição do potencial brasileiro, suas virtudes e limitações, promovendo trocas difíceis de serem mensuradas.

Os ganhos individuais são os mais complexos, pois a manutenção do diálogo entre pares pode acontecer de forma isolada, ao longo dos anos, após a conclusão da graduação, beneficiando a relação professor-aluno, aluno-aluno ou estagiário-empresa. Isso é resultado das relações de confiança geradas, que possibilitarão que sigam interagindo e atuando em novas oportunidades. Caso as ações decorrentes da experiência no exterior não sejam compartilhadas em volume e frequência proporcionais ao peso do investimento governamental, corre-se o risco de que permaneçam restritas ao âmbito dos seus protagonistas.

A experiência internacional em ambiente acadêmico, principalmente na condição de bolsista, pode resultar em imensuráveis momentos de aprendizagem nas áreas específicas de cada estudante, assegurado por ajuda financeira mensal, por conta da bolsa, e também em superação das dificuldades pessoais, linguísticas, de amadurecimento e de mudança de paradigma quanto à visão de mundo e do seu próprio país. Nesta pesquisa, houve relatos de algumas experiências nas quais os alunos tiveram dificuldades alheias à sua vontade, tais como: problemas de atraso no envio do pagamento da bolsa, problemas psicológicos e falta de alinhamento na escolha das disciplinas a serem cursadas no exterior com a sequência dos estudos no retorno, as quais não resultariam em validação alguma de créditos, inclusive com matrícula no exterior em curso distinto do que o estudante realizava no Brasil.

Nas instituições de ensino superior, a mobilidade acadêmica, em especial o Programa Ciência sem Fronteiras, levou à criação de uma cultura da internacionalização, com equipes das áreas de relações internacionais melhor preparadas. Dessa forma, tiveram mais argumentos concretos e ganharam certo status nas suas reivindicações com gestores/reitores das universidades. Com novas estruturas e conhecimento, as equipes de relações internacionais adquiriram mais visibilidade nos projetos de mobilidade acadêmica e, por consequência, maiores oportunidades de realização de convênios e outros projetos ligados à internacionalização. $\mathrm{O}$ alinhamento das equipes da área internacional com os docentes foi também muito significativo, pois representou uma corresponsabilização pelo envio de alunos, o 
compromisso de uma experiência positiva, tendo contado com o suporte e aval dos professores nas instituições de origem. Outro aspecto relevante é a possibilidade de haver impactos nas formas de ensinar e aprender, alavancados pela massa crítica formada pelos estudantes universitários, que poderão aplicar em seus ambientes acadêmicos e profissionais o aprendizado adquirido no exterior.

\section{Nota}

1 Constitui-se em uma parceria interinstitucional com a Universidade do Vale do Rio dos Sinos (Unisinos), a Universidade Federal de Pelotas (UFPel), a Universidade Federal do Rio Grande (Furg), a Universidade do Extremo Sul Catarinense (Unesc), a Universidade Federal do Paraná (UFPRLitoral), a Universidade Católica de Santos (Unisantos), a Universidade Estadual de Feira de Santana (Uefes), a Universidade Estadual Paulista (Unesp/Rio Claro).

\section{Referências}

CHRISTENSEN, Clayton M.; EYRING, Henry J. A universidade inovadora: mudando o DNA do ensino superior de dentro para fora. Trad. Ahyresnede Casarin da Rocha. Porto Alegre: Bookman, 2014.

KNIGHT, Jane. An internationalization model: responding to new realities and challenges. In: WIT, Hans de et al. (Ed.). Higher Education in Latin America: the international dimension. Washington, D.C.: The World Bank, 2005. p. 1-38.

STALLIVIERI, Luciane. Apresentação. In: PEREIRA, Elisabete M. A. et al. (Org.). Internacionalização na educação superior: políticas, integração e mobilidade acadêmica. Blumenau: Edifurb, 2015. p. 15-20.

VERGER, Jacques. As universidades da Idade Média. São Paulo: Editora Universidade Estadual Paulista, 1990.

WIT, Hans de; HUNTER, Fiona. Internationalisation in higher education: future directions. In: WIT, Hans de et al (Ed.). Internationalisation of higher education. Brussels, Belgium: European Parliament's Committee on Culture and Education, 2015. p. 273-288. 